\title{
MicroRNA-126-3p suppresses HeLa cell proliferation, migration and invasion, and increases apoptosis via the PI3K/PDK1/AKT pathway
}

\author{
RYOKO ICHIKAWA*, RIE KAWASAKI, AYA IWATA, SAYAKA OTANI, \\ EIJI NISHIO, HIROYUKI NOMURA and TAKUMA FUJII*
}

Department of Obstetrics and Gynecology, Fujita Health University, School of Medicine, Toyoake, Aichi 470-1192, Japan

Received August 21, 2019; Accepted February 12, 2020

DOI: $10.3892 /$ or.2020.7512

\begin{abstract}
We previously reported that relative to normal cervical mucus, microRNA 126-3p (miR-126-3p) is present in significantly greater amounts in the cervical mucus of patients with overt cervical cancer or precursor lesions. Here, we investigated the effects of enforced miR-126-3p expression in the cervical cancer cell line, HeLa, on proliferation, migration, invasion, apoptosis and protein expression. We transfected HeLa cells with miR-126-3p miRNA and found that proliferation, migration and invasion by cell counting, wound healing, cell migration and invasion assay were significantly reduced in these cells relative to those transfected with a negative control mimic. The levels of phosphoinositide 3 kinase (PI3K), phosphorylated 3-phosphoinositide-dependent protein kinase-1 (p-PDK1) and p-AKT proteins were lower in the miR-126-3p-transfected cells. Phosphorylated 70S6K (p-p70S6K), phosphorylated glycogen synthase kinase $3 \beta$ (p-GSK3 $\beta$ ), phosphorylated S6K (p-S6K), cyclin D1, phosphorylated p21-activated kinase 1 (p-PAK1), Rho associated coiled-coil containing protein kinase 1 (ROCK1), myotonic dystrophy-related CDC42-binding kinases $\alpha(\mathrm{MRCK} \alpha)$ and phospholipase $\mathrm{C} \gamma 1$ (p-PLC $\gamma 1$ ) were also downregulated. This suggests that downstream effectors of the PI3K/PDK1/AKT pathway are targets for inhibition by miR-126-3p. In contrast, apoptotic-related proteins including the BCL-2-associated agonist of cell death (Bad), B-cell lymphoma-extra-large (Bcl-xL) and BCL-2-associated X (Bax), were all upregulated by miR-126-3p, resulting in increased caspase 3/7 activity and apoptosis. Thus, enforced expression of miR-126-3p
\end{abstract}

Correspondence to: Professor Takuma Fujii, Department of Obstetrics and Gynecology, Fujita Health University, School of Medicine, 1-98, Dengakugakubo, Kutsukakecho, Toyoake, Aichi 470-1192, Japan

E-mail: fujiit44@fujita-hu.ac.jp

*Contributed equally

Key words: HeLa cells, microRNA, cell migration, apoptosis, signal transduction inhibited cell migration and invasion and also induced apoptosis by regulating the PI3K/PDK1/AKT pathway in HeLa cells. Hence, high levels of miR-126-3p may inhibit cervical carcinogenesis, and targeting the PI3K/PDK1/AKT pathway via miR-126-3p could represent a new approach for treating patients with cervical cancer.

\section{Introduction}

Cervical cancer is the fourth leading cause of tumor-related mortality and is the most common gynecological tumor worldwide (1). Persistent infection with a subset of human papillomaviruses (HPVs), denoted as 'high-risk' HPVs, plays a critical role in the initiation and development of cervical cancer. A cascade of abnormal events occurs during cervical carcinogenesis, including the induction of genomic instability, dysregulation of cell proliferation, disruption of cell cycle control mechanisms and aberrant expression of certain oncogenes and tumor-suppressor genes (2). Upregulated phosphoinositide 3 kinase (PI3K), AKT and the mammalian target of rapamycin (mTOR) via the mTOR pathway have been reported in metastatic and recurrent cervical cancer patients. Accordingly, a clinical benefit of therapy targeted to these cell signaling pathways has been reported in phase I and II clinical trials (3-5), consistent with the finding that AKT inhibitors promote cell death in cervical cancer (6).

MicroRNAs (miRNAs) are endogenous, 19-25mer, small non-coding RNAs that regulate gene expression by base-pairing to the 3'-untranslated region (3'-UTR) of target messenger RNAs (mRNAs) (7). miRNAs regulate gene expression at the post-transcriptional level, subsequently triggering translational repression or mRNA destabilization. MicroRNA-126-3p (miR-126-3p), which has been identified in many types of cancer including lung, breast, gastric, colorectal, glioblastoma, bladder and prostate, may act either as a tumor suppressor by inhibiting oncogenes (8-17) or as a tumor promoter by inhibiting tumor suppressors $(18,19)$. In cervical cancer, disparate data on the levels of miR-126-3p have been reported, either downregulation in some studies $(12,14,20,21)$ while upregulation in others $(15,22)$, albeit under different experimental conditions. Previous studies have shown that miR-126-3p can target a site in the PI3K subunit p85 $\beta$ (PIK3R2) 3'-UTR, not 
only in different types of cancer (23-26) but also in benign diseases $(27,28)$. p85 $\beta$ also acts as an important upstream regulatory factor in the AKT-dependent signaling pathway. However, the involvement of miR-126-3p in cervical cancer and the molecular mechanisms of its action associated with the PI3K/PDK1/AKT pathway have not yet been fully established. Using an in vitro model, we examined the molecular mechanisms potentially responsible for the tumor-suppressor activity of miR-126-3p in cervical cancer, focusing on its action via the $\mathrm{PI} 3 \mathrm{~K} / \mathrm{PDK} 1 / \mathrm{AKT}$ signaling pathway.

\section{Materials and methods}

Cell culture. The human cervical cancer cell line HeLa was obtained from Keio University in Japan, and cultured in Ham's F12 medium (Wako Pure Chemical, Osaka, Japan) supplemented with $10 \%$ fetal bovine serum (FBS; Gibco Life Technologies; Thermo Fisher Scientific, Inc.) and 1\% penicillin/streptomycin (Wako Pure Chemical). Cells were incubated at $37^{\circ} \mathrm{C}$ in $5 \% \mathrm{CO}_{2}$. To confirm the identity of the analyzed cell line, we performed short tandem repeat (STR) genotyping, which revealed correspondence with more than $80 \%$ of the markers tested. We found no mycoplasma in cells tested with MycoAlert mycoplasma detection kit (Lonza).

Plasmid construction and mimic miRNA. A dual luciferase reporter system, the psiCheck2 vector system (Promega) with two luciferase enzymes was employed here (one from Renilla containing the experimental sequence and another from firefly containing the internal control). The psiCHECK2-miR126-3p (Assay ID: MIC0000445) vector contains the complementary sequence of hsa-miR-126-3p (MiRBase ID MIMAT0000445) inserted into the psiCHECK-2 vector at the 3 'end of the coding sequence of the Renilla reniformis luciferase gene in Fig. S1 (Promega). Mature miRNA molecules (mirVana miRNA hsa-miR-126-3p mimic; assay ID: MC12841) and Negative Control mimic (mirVana miRNA Mimic Negative Control \#1) were purchased from Thermo Fisher Scientific, Inc. The target sequence and its vector construct are depicted in Fig. S1.

Transfection. HeLa cells were trypsinized, diluted with medium without antibiotics, and seeded into 96-well culture plates $\left(2 \times 10^{4}\right.$ cells/well) or 6 -well culture plates $\left(5 \times 10^{5}\right.$ cells/well $)$. HeLa cells were transfected with Lipofectamine 2000 transfection reagent (Invitrogen; Thermo Fisher Scientific, Inc.) at a 2:1 Lipofectamine/DNA ratio in Opti-Minimal Essential Serum-Free medium (Opti-MEM medium; Gibco Life Technologies; Thermo Fisher Scientific, Inc.). We then transfected the cells with a mixture of psiCHECK2-miR126-3p and $100 \mathrm{nM}$ hsa-miR-126-3p mimic or $100 \mathrm{nM}$ negative control (NC) mimic. Cells were incubated with transfection reagent/DNA/mimic for $4 \mathrm{~h}$ followed by replacement with regular culture medium. Transfection with the psiCHECK2-miR126-3p vector was performed in every experiment in order to assure the same conditions for transfection and to monitor transfection efficiencies in all experiments.

Dual-luciferase reporter assay. At $24 \mathrm{~h}$ post-transfection, Renilla and firefly luciferase activities were measured by luminometer in the same plate using the Dual-Glo Luciferase
Assay System kit (Promega); 2030 ARVO X5 (Perkin Elmer). Renilla luciferase activity values were normalized for transfection efficiency using the corresponding firefly luciferase activity as an internal control. Three independent transfection experiments were performed, each in triplicate.

CCK- 8 assay. Cell proliferation was measured with the Cell Counting Kit-8 (CCK-8, Dojindo Molecular Technologies, Inc., Japan). After transfection, $10 \mu \mathrm{l}$ of CCK- 8 solution [WST-8: 2-(2-methoxy-4-nitrophenyl)-3-(4-nitrophenyl)-5(2,4-disulfophenyl)-2H-tetrazolium, mono-sodium salt], was added to each well at 24, 48 and $72 \mathrm{~h}$. The plates were then incubated for $2 \mathrm{~h}$ at $37^{\circ} \mathrm{C}$ in $5 \% \mathrm{CO}_{2}$. Absorbance was measured using a Benchmark microplate reader (Bio-Rad Laboratories) at $450 \mathrm{~nm}$. Each assay was independently performed 3 times in triplicate. Cell proliferation was calculated by subtracting the absorbance values of the media alone (background level) from the samples.

Wound healing assay. HeLa cells were seeded at a concentration of $5 \times 10^{5}$ cells in $2 \mathrm{ml}$ of Ham's F12 medium supplemented with 5\% FBS in 6-well plates. The following day, the plasmid vector $(4 \mu \mathrm{g})$ was transfected with the hsa-miR-126-3p mimic $(100 \mathrm{nM})$ or the negative control mimic (100 nM). Scratch wounds were made $24 \mathrm{~h}$ after transfection on a confluent monolayer of cultured cells with a sterile 200- $\mu$ l-pipette tip and photographed at $0,18,24$ and $48 \mathrm{~h}$ using a digital camera system coupled to an Axio-Observer microscope (Carl Zeiss Microscopy). Wound closure was measured by ImageJ 1.60 software (NIH, National Institutes of Health) and expressed as Wound closure rate $(\%)=$ migrated cell surface area/total surface area $x 100$. At least 5 points in each of 3 random fields per well were examined and three independent experiments were performed. All results were recorded as the means of triplicate assays with standard deviation.

Cell migration and invasion assays. Cells were seeded in the upper chamber of a Transwell vessel with a coated Matrigel membrane (to assess invasion; Corning Costar Corp.) or without a coating (to assess migration). At $24 \mathrm{~h}$ post-transfection, in both assays, $2 \times 10^{5}$ cells in $200 \mu \mathrm{l}$ serum-free medium were reseeded into the upper chamber, and $750 \mu 1$ of Dulbecco's modified Eagle's medium (DMEM; Wako Pure Chemical) supplemented with $20 \%$ FBS was added to the lower chamber as a chemoattractant. After $48 \mathrm{~h}$, non-migrating and non-invading cells on the upper surface of the membrane were mechanically removed by wiping with a moistened cotton swab. Cells that migrated and invaded into the lower surface of the membrane were stained with Hemacolor Stain Set (Merck, Darmstadt, Germany) according to the manufacturer's instructions. The membranes were then plated on glass slides with the cells on the top. The slides were photographed at a magnification of $\mathrm{x} 100$, using a light microscope and a digital color camera (Olympus BX43 with DP70; Olympus Optical Co.). The migrating and invading cells were counted in five randomly selected visual fields and analyzed using NIH Image J 1.60 software. Data are expressed as the percentage of invasion through the Matrigel matrix and membrane relative to migration through the control membrane. Invasion percentage was calculated as [(the mean number of cells that invaded 
the Matrigel insert)/(the mean number of cells that migrated through the non-coated insert membrane)] x100.

Apoptosis assay. At $24 \mathrm{~h}$ post-transfection, HeLa cells were seeded in triplicate at $5 \times 10^{3}$ cells/well in a 96 -well plate. After $24 \mathrm{~h}$, caspase 3/7 activity was measured in the same plate using a Caspase-Glo 3/7 Assay kit (Promega) and a luminometer (Perkin Elmer) according to the manufacturer's instructions. Luminometer readings were taken $1 \mathrm{~h}$ after adding the caspase 3/7 reagent. Background readings were determined from wells containing culture medium without cells. The data were normalized to the controls. Three independent experiments were performed, each in triplicate.

Antibodies. Antibodies for immunoblotting were obtained from Cell Signaling Technology and Santa Cruz Biotechnology. The following primary antibodies were used in this study (all rabbit): Anti-PI3 kinase p85 (dilution 1:500; cat. no. 4257), anti-p110 $\alpha$ (dilution 1:1,000; cat. no. 4249), anti-AKT (dilution 1:1,000; cat. no. 4691), anti-p-Akt (Ser473) (dilution 1:1,000; cat. no. 4060), anti-PDK1 (dilution 1:1,000; cat. no. 5662), anti-p-PDK1 (dilution 1:1,000; cat. no. 3438), anti-p70S6 kinase (dilution 1:1,000; cat. no. 2708), anti-p-p70S6 kinase (dilution 1:1,000; cat.no.9234), anti-S6ribosomal protein (dilution 1:1,000; cat. no. 14467), anti-p-S6 ribosomal protein (dilution 1:1,000; cat. no. 4858), anti-GSK3 $\beta$ (dilution 1:1,000; cat. no. 12456), anti-p-GSK-3 $\beta$ (dilution 1:1,000; cat. no. 5558), anti-cyclin D1 (dilution 1:500; cat. no. 2978), anti-ROCK1 (dilution 1:1,000; cat. no. 4035), anti-PAK1 (dilution 1:1,000; cat. no. 2602), anti-p-PAK1 (dilution 1:500; cat. no. 2601), anti-PLC $\gamma$ (dilution 1:1,000; no. 5690), anti-p-PLC $\gamma$ (dilution 1:500; cat. no. 14008), anti-Bad (dilution 1:1,000; cat. no. 5023), anti-Bax (dilution 1:1,000; cat. no. 9239), anti-Bcl-xL (dilution 1:1,000; cat. no. 2764), anti- $\beta$-actin (dilution 1:2,000; cat. no. 4970), and anti-MRCK $\alpha$ (dilution 1:100; cat. no. sc-374568). The secondary antibody was horseradish peroxidase (HRP)-conjugated anti-rabbit IgG antibody (cat. no. 7074).

Western blotting. HeLa cells were transfected and harvested after 48 or $72 \mathrm{~h}$ in a 6 -well plate at $5 \times 10^{5}$ cells/well. Cells were washed twice with ice-cold phosphate-buffered saline (PBS) and lysed using RIPA lysis buffer (Santa Cruz Biotechnology) containing $1 \mathrm{mM}$ PMSF, $1 \mathrm{mM}$ Na-orthovanadate and $1 \mathrm{X}$ complete protease inhibitor cocktail (Roche Diagnostics). After a 30-min incubation on ice, cell lysates were triturated and centrifuged at $20,630 \mathrm{x}$ g for $15 \mathrm{~min}$ at $4^{\circ} \mathrm{C}$. The clear supernatants were saved as whole-cell lysate. Protein concentration was determined using Pierce BCA Protein Assay Kits (Thermo Fisher Scientific, Inc.). Total cell lysates $(20 \mu \mathrm{g})$ in each lane were mixed with 6X SDS sample buffer containing dithiothreitol (DTT). Samples were incubated at $96^{\circ} \mathrm{C}$ for 5 min before being loaded onto $10 \%$ SDS-polyacrylamide gels (ATTO Corp.) and electrophoresed for $90 \mathrm{~min}$ at $18 \mathrm{~mA}$. Gels were transferred to polyvinylidene difluoride membranes (PVDF; ATTO Corp.) at $70 \mathrm{~V}$ for $1 \mathrm{~h}$ and then blocked with blocking buffer (\#AE-1476 EzBlock BSA; ATTO Corp.) for $1 \mathrm{~h}$ at room temperature. All antibodies were diluted in Tris-buffered saline containing $0.1 \%$ Tween-20 (TBS-T). Membranes were incubated overnight at $4^{\circ} \mathrm{C}$ with primary antibodies and washed with TBS-T before incubation with

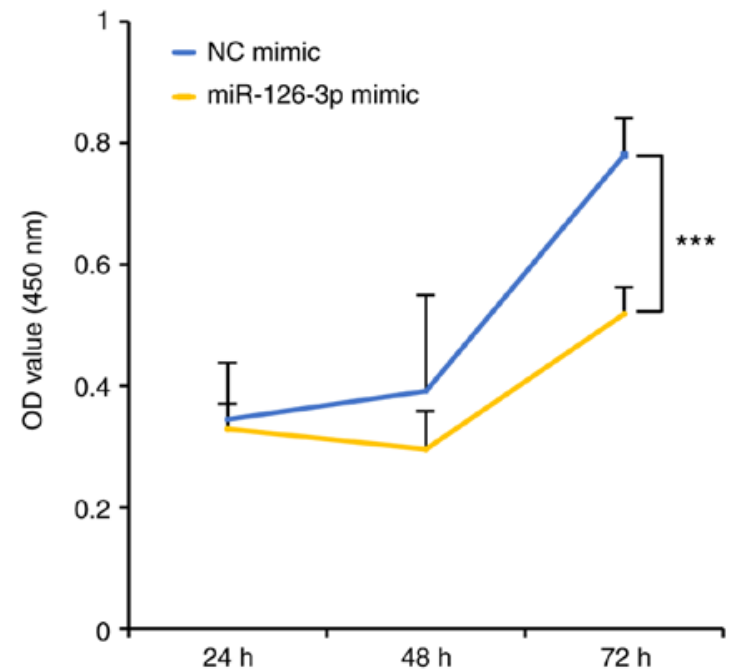

Figure 1. Suppression of proliferation of HeLa cells following transfection with a miR-126-3p mimic. The transfected mimics [miR-126-3p mimic and negative control (NC mimic)] in HeLa cells were assayed by CCK- 8 assay at 24,48 and $72 \mathrm{~h}$ after transfection. Data were obtained from at least three independent experiments. A significant difference was noted between the miR-126-3p and NC groups. ${ }^{* * *} \mathrm{P}<0.001$.

horseradish peroxidase (HRP)-conjugated secondary antibody at room temperature for $1 \mathrm{~h}$. The blots were examined using an ECL Prime Western Blotting Detection System (GE Healthcare Life Science) according to the manufacturer's instructions, and visualized using the Image Quant LAS 4000 Mini image analysis system (GE Healthcare Life Science). Band quantification was performed using NIH ImageJ 1.60 software and protein levels were normalized to $\beta$-actin levels.

Statistical analysis. Statistical analysis was performed using SPSS 22.0.0.0 software (IBM Corp.). Data were recorded as mean \pm SD. The independent samples Student t-test was used for comparison. A P-value of $\leq 0.05$ or less $(\mathrm{P}<0.001$; $\mathrm{P}<0.01)$ was considered significant.

\section{Results}

Use of the reporter plasmid to study the function of miR-126-3p. The relative transcriptional activity (Rlu activity/Flu activity) was $0.063 \pm 0.014$ in the HeLa cells transfected with the miR-126-3p mimic compared to $0.65 \pm 0.13$ in the $\mathrm{NC}$ mimic group (Fig. S2). Renilla reporter activity was significantly reduced by the miR-126-3p mimic compared to the NC mimic; $\mathrm{P}<0.001)$. This finding documents that the miR-126-3p mimic binds to the 3'-untranslated region (3'-UTR) of the Renilla luciferase reporter gene and thus contributes to its suppression. We then adopted this experimental system to investigate potential biological effects exerted by miR126-3p in HeLa cells that may be relevant to cervical carcinogenesis.

Suppression of proliferation by transfection with miR-126-3p. To investigate the functional role of miR-126-3p in the proliferation of HeLa cells, we used the CCK- 8 assay after transfection with the miR-126-3p mimic or the negative control (NC) mimic. Compared with the NC, the cells transfected with the 126-3p mimic showed lower cell growth, indicating 
A
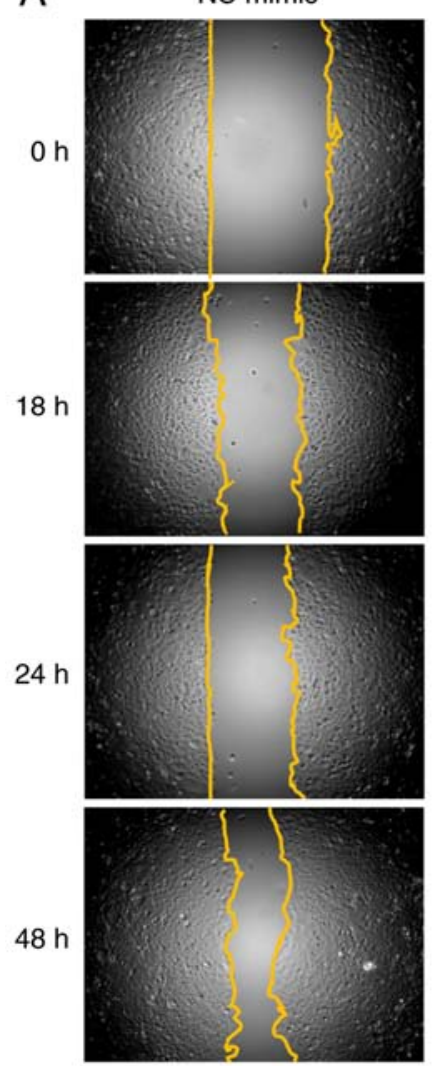

miR-126-3p mimic
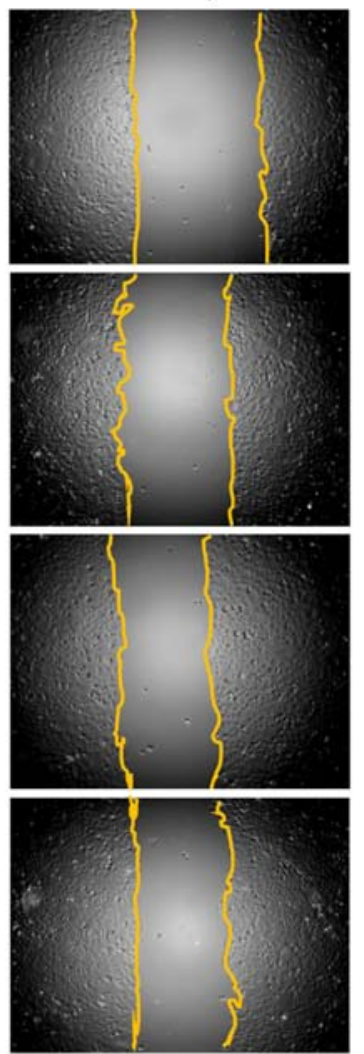

B

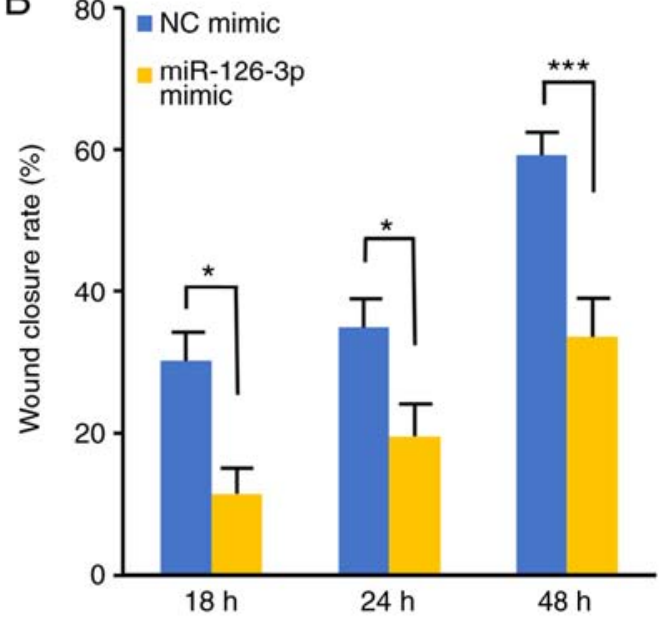

Figure 2. Suppression of cell migration by transfection with miR-126-3p, as measured by wound healing assay. HeLa cells were transfected with miR-126-3p or the negative control (NC) mimic. Representative images of scratches were taken at 0, 18, 24 and $48 \mathrm{~h}$. Monolayers of HeLa cells were scratched with a pipette tip $24 \mathrm{~h}$ after transfection. (A) Images of wound repair were captured at $0,18,24$ and $48 \mathrm{~h}$. The percentage of wound closure was normalized to wound area at $0 \mathrm{~h}$. Wound healing area over time was quantified using ImageJ. (B) Data were obtained from the mean of three independent experiments. Error bars represent standard deviations. Statistical analysis was conducted by $\mathrm{t}$-test. ${ }^{*} \mathrm{P}<0.05,{ }^{* * * *} \mathrm{P}<0.001$ vs. the NC group.

suppression of proliferation (Fig. 1). The degree of suppression by the miR-126-3p mimic reached statistical significance at $72 \mathrm{~h}(\mathrm{P}<0.001)$.

miR-126-3p suppresses migration and invasion. To determine whether miR-126-3p also affects migration, we used a wound healing assay to examine the effects of miR-126-3p transfection (Fig. 2A and B). The wound scratches healed significantly more slowly when the HeLa cells were transfected with the miR-126-3p mimic than with the NC mimic at 18, $24(\mathrm{P}<0.05)$ and $48 \mathrm{~h}(\mathrm{P}<0.001)$. Inhibition of migration and invasion was confirmed by Transwell assays (Fig. 3A-D). As shown in Fig. 3B, transfection with the miR-126-3p mimic led to significantly reduced migration capacity than that in the $\mathrm{NC}$ ( $70.9 \pm 0.41$ vs. $89.7 \pm 5.5$ cells per field, respectively; $\mathrm{P}<0.01$ ). Significant differences in invasion were also observed between the miR-126-3p mimic-transfected cells and NC, as shown in Fig. 3D $(\mathrm{P}<0.001)$. The invasion rate recorded was $31.8 \%$ (range $21.8-40.4 \%$ ) and $61.3 \%$ (range 52.9-70.4\%) at $72 \mathrm{~h}$ in the miR-126-3p mimic and NC mimic transfectants, respectively.

miR-126-3p suppresses the PI3K/PDK1/AKT pathway. We showed above that the role of miR-126-3p is as a tumor suppressor that regulates proliferation, migration, and invasion in HeLa cells. To elucidate the underlying molecular mechanisms responsible for these effects of miR-126-3p, we analyzed the expression of components of the PI3K/PDK1/AKT signaling pathway. Western blotting revealed that transfection of the miR-126-3p mimic in the HeLa cells decreased the expression of multiple PI3K/PDK1/AKT pathway proteins, including p85 $\beta$, p1 10 $\alpha$, phosphorylated (p)-3-phosphoinositide-dependent protein kinase-1 (PDK1) and phosphorylated (p)-AKT, at 48 and $72 \mathrm{~h}$ after transfection (Fig. 4A and B). Expression levels of phosphorylated glycogen synthase kinase $3 \beta$ (p-GSK3 $\beta$ ), cyclin D1, phosphorylated p70S6K (p-p70S6K) and phosphorylated S6K (p-S6K), which are all located downstream of the AKT pathway, were also significantly reduced relative to the NC mimic transfected cells. We also focused on PDK1 and its downstream pathway (Fig. 5A and B). To further determine the contribution of PI3K/PDK1 inactivation to downstream signaling, we examined the PDK1-related protein, myotonic dystrophy-related CDC42-binding kinase $\alpha(\mathrm{MRCK} \alpha)$, Rho-associated coiled-coil-containing protein kinase 1 (ROCK1), phospholipase C $\gamma 1$ (PLC $\gamma 1)$ and p21-activated kinase 1 (PAK1). We found lower levels of all these proteins in cells transfected with the miR-126-3p mimic than with the NC mimic. The kinetics of the altered expression of these proteins between 48 and $72 \mathrm{~h}$ is important; proteins located upstream of the pathway, such as p85 $\beta$, p110 $\alpha$, p-PDK1, p-AKT, p-GSK3 $\beta$, cyclin D1, MRCK $\alpha$, ROCK1 and p-PLC $\gamma 1$ were decreased $48 \mathrm{~h}$ after transfection and gradually recovered at $72 \mathrm{~h}$. In contrast, proteins located downstream of this pathway, such 
A
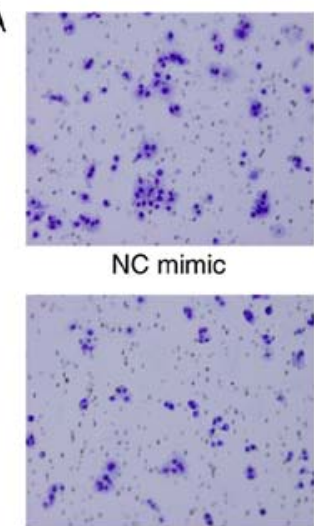

miR-126-3p mimic

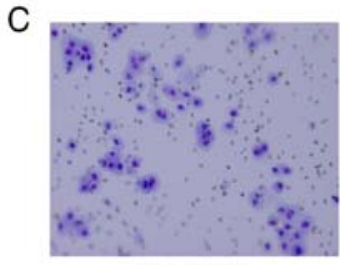

NC mimic

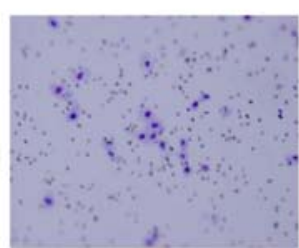

miR-126-3p mimic
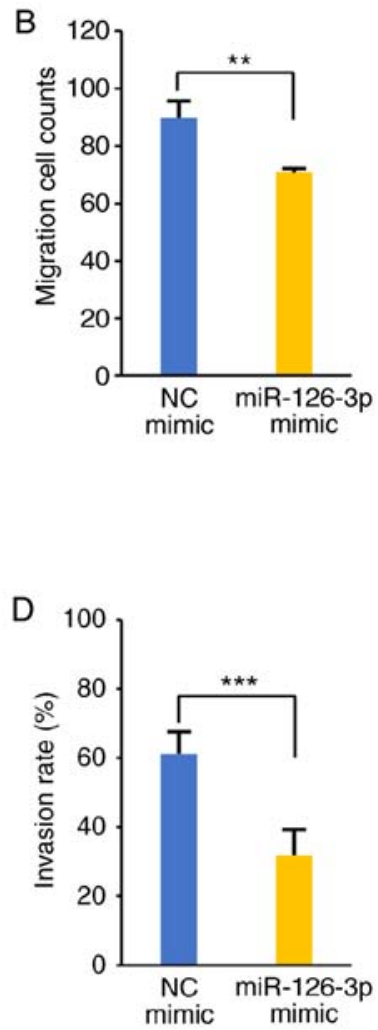

Figure 3. miR-126-3p-suppresses migration and invasion of HeLa cells as assessed by the Transwell assay. After $48 \mathrm{~h}$ of incubation, non-migrating and non-invading cells on the upper surface of the membrane were mechanically removed by wiping with a moistened cotton swab. (A) Cells that migrated were stained with the Hemacolor Stain Set (Merck). Magnification, x100 (specific details in Materials and methods). (B) Mean number of migratory cells in three independent experiments. Bar indicates standard deviation ${ }^{* *} \mathrm{P}<0.01$. (C) Representative images of invasive cells. After $48 \mathrm{~h}$ of incubation, invasive cells were stained with the Hemacolor Stain Set (Merck) Magnification, x100 (details in Materials and methods). (D) Invasion rate of miR-126-3p transfectants and NC group. The mean number of invasive cells in three independent experiments is shown. Bar indicates standard deviation. *** $\mathrm{P}<0.001$.

as p-p70S6K, p-S6 and p-PAK1, were reduced 24 later, at $72 \mathrm{~h}$ post-transfection.

miR-126-3p-induced apoptosis. Finally, we investigated the apoptosis in HeLa cells transfected with the miR-126-3p mimic. Western blotting demonstrated that the BCL-2-associated agonist of cell death (Bad) and BCL-2-associated X (Bax) proteins were upregulated, whereas B-cell lymphoma-extra large $(\mathrm{Bcl}-\mathrm{xL})$ protein expression was downregulated. The miR-126-3p mimic consequently increased caspase-3/7 activity in the HeLa cells (Fig. 6A and B).

\section{Discussion}

We previously found that miR-126-3p is highly expressed in patients with overt cervical cancer or precursor lesions compared with normal cells (22). Accordingly, we hypothesized that miR-126-3p promotes carcinogenesis. However, we observed that levels of miR-126-3p in patients with cervical

cancer fluctuate (22). We also found variability in the amounts of miR-126-3p in cervical cancer cells themselves (Fig. S3). Hence, as expression of miR-126-3p is not ubiquitous in vivo or in vitro in cervical cancer, we hypothesized that endogenous miR-126-3p does not necessarily play a critical role in carcinogenesis. Indeed, in the present study, in contrast, we found that the results of enforced expression of miR-126-3p reflected characteristics of anticancer activity in vitro. We thus aimed to ascertain how miR-126-3p is involved in cervical carcinogenesis. Initially we used the DIANA-miRPath V3.0: miRNA pathway analysis program via a web-server (29), which indicated that miR-126-3p is associated with tPIK3R2 and AKT1 in the mTOR signaling pathway, a candidate pathway for targeted therapy in cervical cancer (30-32). Therefore, we investigated the function of $\mathrm{miR}-126-3 \mathrm{p}$ in relation to the $\mathrm{PI} 3 \mathrm{~K} / \mathrm{PDK} 1 / \mathrm{AKT}$ signaling pathway in the cervical cancer cell line HeLa. The highest frequency of mutation of the $P I 3 \mathrm{~K}$ gene in cervical cancer is $20-30 \%$, and its mutation is a late event during cervical carcinogenesis $(33,34)$. In the present study, we used the cervical cancer cell line HeLa since these cells are suitable for transfection experiments due to their ability to highly express the luciferase gene with a reporter plasmid; 10.3-fold increase (Fig. S2). This also indicated that enforced miR-126-3p was biologically active in the cells, despite that direct overexpression of miR-126-3p by RT-PCR was not shown. There is no mutation in, nor amplification of, the PI3K gene in HeLa cells $(6,35,36)$. Here, we report that enforced expression of miR-126-3p inhibited proliferation, migration and invasion in the transfected HeLa cells. As expected, the levels of proteins including $\mathrm{p} 85 \beta$, p110 $\alpha$, p-PDK1, p-AKT, p-p70S6K, p-S6, p-GSK3 $\beta$, cyclin D1, MRCK $\alpha$, ROCK1, p-PAK 1 and p-PLC $\gamma 1$ were decreased after transfection of the miR-126-3p mimic. Notably, p85 $\beta$ was significantly downregulated both at 48 and $72 \mathrm{~h}$, whereas, p110a downregulation was noted at $48 \mathrm{~h}$ only. Thus, miR-126-3p mainly exerts its effects via inhibition of $\mathrm{p} 85 \mathrm{~b}$.

Akt is one of the most frequently hyperactivated kinases in human cancers and plays an important role in cell migration (37). S6K1 is a serine-threonine kinase that is implicated in the regulation of several cellular processes, such as growth, survival and metabolism (38). The main target of S6K is ribosomal protein S6, a component of the 40S ribosomal subunit. S6 is essential for protein synthesis and cell cycle progression. S6K shows increased activity in several cancer cells and has been associated with resistance to drugs and chemotherapeutic treatment, emphasizing the role of these proteins in carcinogenesis. S6K1 inhibition prevents the migration of breast tumor cells, suggesting its important role in metastatic breast cancer. The S6K1 inhibitor, PF-4708671, was found to markedly reduce cell migration and invasion, suggesting that this drug may be suitable for anti-metastatic therapy for breast cancer (39). GSK-3 is associated with various signaling pathways, including Wnt/ $\beta$-catenin, PI3K/PTEN/Akt/mTORC, Ras/Raf/MEK/ERK, Hedgehog, Notch and TP53, all related to epithelial-mesenchymal transition and to cancer stem cells (40). Phosphorylated AKT induces phosphorylated GSK3 $\beta$ (inactive form). Dephosphorylated GSK3 $\beta$ (active form) inhibits cyclin D1 $(41,42)$ and the inactive form of phosphorylated GSK3 $\beta$ induces cyclin D1. Therefore, miR-126-3p-downregulated phosphorylated AKT is likely to inhibit cell turnover 

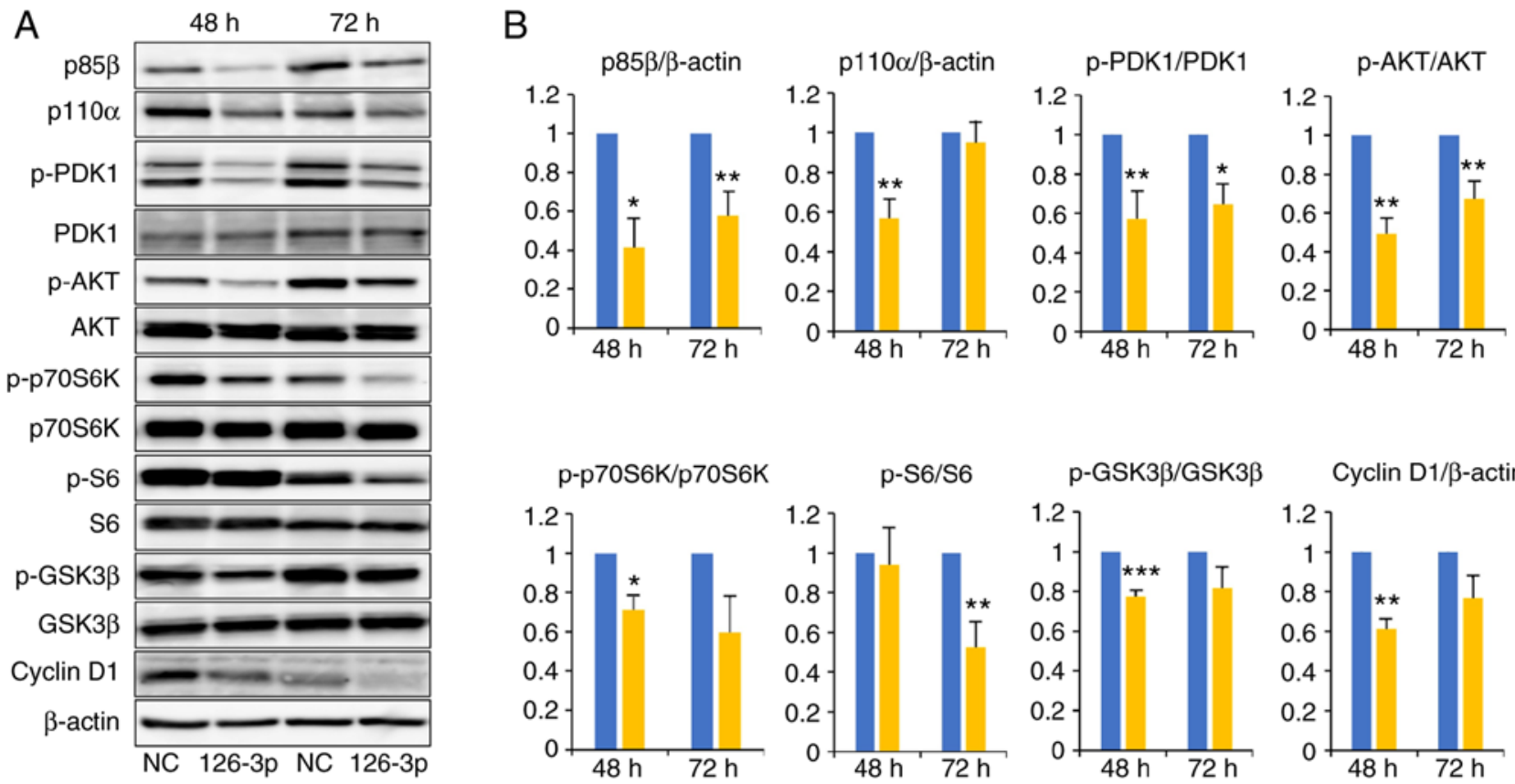

p-p70S6K/p70S6K

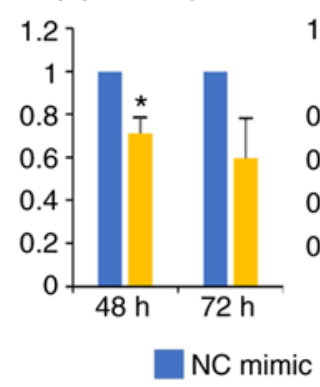

$\mathrm{p}-\mathrm{S} 6 / \mathrm{S} 6$

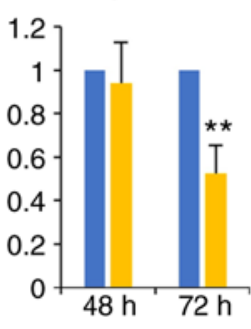

p-GSK3 $\beta / G S K 3 \beta$

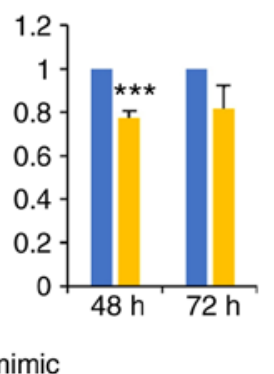

Cyclin D1/ $\beta$-actin

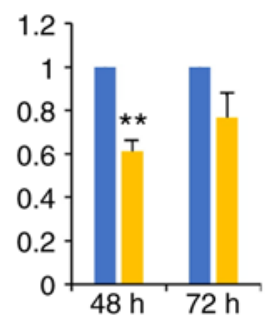

Figure 4. Amounts of proteins in the PI3K/AKT pathway including p85 $\beta$, p110 $\alpha$, p-PDK1, p-AKT, p-p70S6K, p-S6, p-GSK3 $\beta$ and cyclin D1 are decreased in HeLa cells following transfection with the miR-126-3p mimic. (A) Cells were harvested 48 or $72 \mathrm{~h}$ after transfection with miR-126-3p (126-3p) or negative control (NC) mimic concomitant with the reporter plasmid psiCHECK2-miR126-3p. Representative western blots of the protein levels of the AKT/PI3K pathway are shown. (B) Quantification of the western blots by densitometry. Quantification of signals is presented as 'fold-change' relative to levels of $\beta$-actin or phosphorylated (p-) protein vs. total protein. All experiments were performed in triplicate. ${ }^{*} \mathrm{P}<0.05,{ }^{* *} \mathrm{P}<0.01$ and ${ }^{* * *} \mathrm{P}<0.001$, respectively. No asterisk indicates a non-significant difference. PI3K, phosphoinositide 3 kinase; AKT, protein kinase B; PDK1, 3-phosphoinositide-dependent protein kinase-1; GSK3 $\beta$, glycogen synthase kinase $3 \beta$.

A

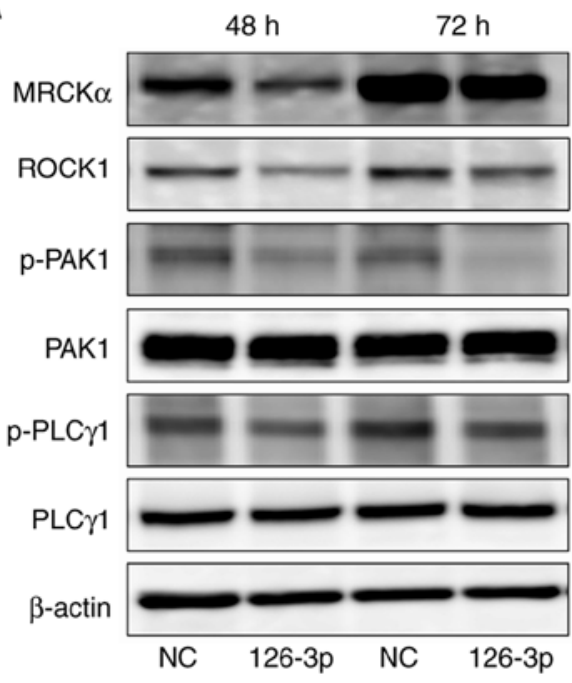

B
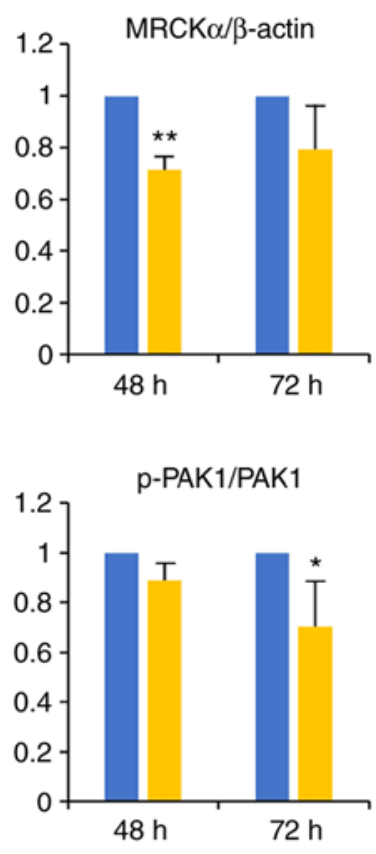

NC mimic
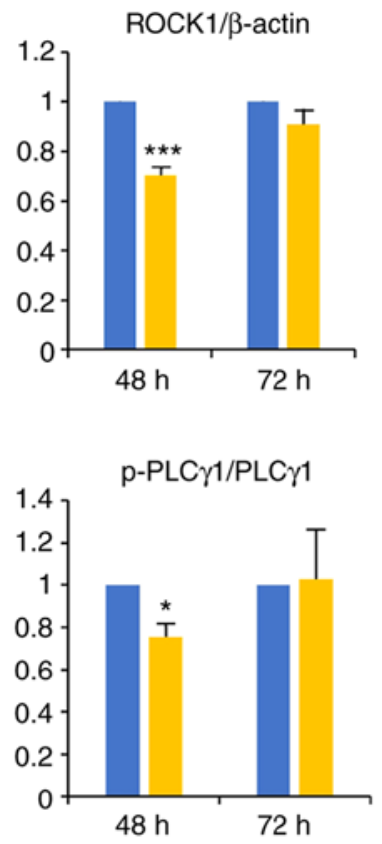

miR-126-3p mimic

Figure 5. Amounts of proteins in the PI3K/PDK1/AKT pathway including MRCK $\alpha$, ROCK1, PAK1 and PLC $\gamma 1$ are decreased in HeLa cells following transfection with the miR-126-3p mimic. (A) Cells were harvested 48 or $72 \mathrm{~h}$ after transfection with miR-126-3p or the negative control (NC) mimic concomitant with the reporter plasmid psiCHECK2-miR126-3p. Representative western blot showing levels of the proteins in the AKT/PDK1/PI3K pathway are shown. (B) Quantification of the western blot by densitometry. Quantification of signals presented as fold-change relative to levels of $\beta$-actin or phosphorylated (p-) protein vs. total protein. All experiments were performed in triplicate. ${ }^{*} \mathrm{P}<0.05,{ }^{* *} \mathrm{P}<0.01$ and ${ }^{* * * *} \mathrm{P}<0.001$, respectively. No asterisk indicates a non-significant difference. PI3K, phosphoinositide 3 kinase; AKT, protein kinase B; PDK1, 3-phosphoinositide-dependent protein kinase-1; MRCK $\alpha$, myotonic dystrophy-related CDC42-binding kinases $\alpha$; ROCK1, Rho associated coiled-coil containing protein kinase 1; PAK1, p21-activated kinase 1; PLC $\gamma 1$, phospholipase $\mathrm{C} \gamma 1$. 


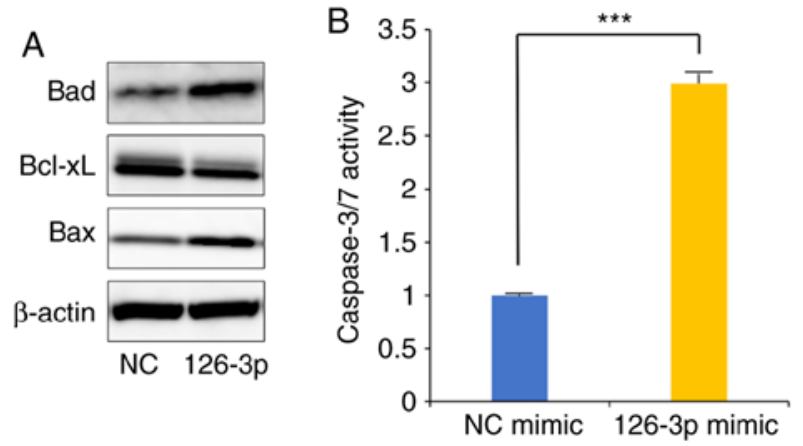

Figure 6. Aberrant expression of proteins including Bax, Bad and Bcl-xL in HeLa cells following transfection with the miR-126-3p mimic. (A) Cells were harvested after transfection with the miR-126-3p (126-3p) or negative control (NC) mimic or concomitant with the reporter plasmid psiCHECK2-miR126-3p. Representative western blots showing Bad, Bcl-xL and Bax. (B) HeLa cells transfected with the miR-126-3p or NC mimic were assayed for caspase 3/7 activity. Data are from three independent experiments. Bars indicate standard deviation. ${ }^{* * *} \mathrm{P}<0.001$. Bad, $\mathrm{Bcl}-2$-associated agonist of cell death; Bcl-xL, B-cell lymphoma-extra-large; Bax, Bcl-2-associated X.

through downregulation of cyclin D1. Furthermore, inhibition of the PI3K/Akt pathway can lead to the apoptosis of cervical cancer cells (43). Our results demonstrated that inhibition of the PI3K/Akt pathway by miR-126-3p promoted caspase 3/7 activity through the control of anti-apoptotic proteins such as Bcl-xL and pro-apoptotic proteins including Bax and Bad. Activated AKT and mTOR are indicators of poor prognosis in cervical cancer $(31,44)$. In clinical trials, PI3K/AKT/mTOR inhibitors have been used as molecular targeted therapies in cervical cancer, and the PI3K/AKT inhibitor, LY294002 was found to increase radiation sensitivity in cervical cancer cell lines (45). The PI3K/mTOR inhibitor, NVP-BEZ235, was also found to exert an effect on cervical cancer cells (46). Recent research has revealed that $\mathrm{Akt} / \mathrm{mTOR}$ signaling promotes neuroendocrine cervical cancer, which has an extremely poor prognosis, suggesting that this pathway may be utilized for novel anticancer treatment strategies (47).

We found that miR-126-3p suppresses PDK1 and its downstream proteins. PDK1 regulates cell migration via AKT, PAK1, ROCK1, MRCK $\alpha$ and PLC $\gamma 1$ (48) and is centrally involved in cell signaling via regulation of PI3K signaling and activation of multiple downstream effectors. PAK1 can be activated by phosphorylation of threonine 423 by phosphorylated PDK1. Both PDK1 and PAK1 have been reported to regulate the migration of vascular smooth muscle cells. PDK1 regulates cell migration and invasion by activating ROCK1 and MRCK $\alpha$ and PLC $\gamma 1$. Overexpression of PDK1 correlates with a more aggressive cancer phenotype and poorer patient prognosis (44). Thus, PDK1 targeting could also provide an effective therapeutic intervention in cancer where migration and invasion play a crucial role in prognosis. Here, we presented data on the kinetics of effects on protein expression after transfection that are consistent with the hierarchy of this pathway (Fig. 7).

There are some limitations to the present study. Although many cervical cancer cells are available for in vitro experiments, we used HeLa cells. This was because the combination of HeLa cells, transfection reagents, and miRNA mimics used in our experiments produced the highest transfection rates (data not shown). If transfection efficiency is improved,

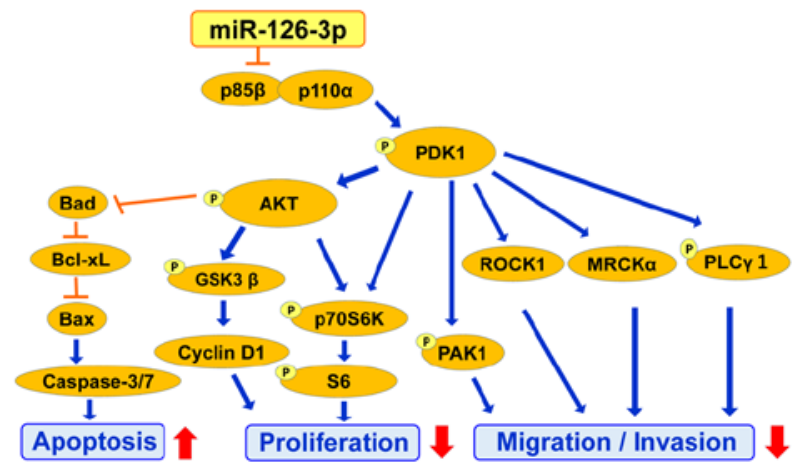

Figure 7. A schematic model of the underlying mechanisms of miR-126-3p-mediated suppression of proliferation, migration and invasion through the PI3K/PDK1/AKT pathway. miR-126-3p suppresses progression of cervical cancer cells through the PI3K/PDK1/AKT signaling pathway. The AKT pathway is associated with proliferation of cells through its downstream signaling pathway including GSK3 $\beta$, cyclin D1, p70S6K and S6 activation. The PDK1 pathway is associated with migration and invasion of cells through mediators of its downstream signaling pathway including p70S6K, MRCK $\alpha$, ROCK1, PLC $\gamma-1$ and PAK1. PI3K, phosphoinositide 3 kinase; AKT, protein kinase B; PDK1, 3-phosphoinositide-dependent protein kinase-1; GSK3 $\beta$, glycogen synthase kinase $3 \beta$; MRCK $\alpha$, myotonic dystrophy-related CDC42-binding kinases $\alpha$; ROCK1, Rho associated coiled-coil containing protein kinase 1; PAK1, p21-activated kinase 1; PLC $\gamma 1$, phospholipase C $\gamma 1$; Bad, Bcl-2-associated agonist of cell death; Bcl-xL, B-cell lymphoma-extra-large; Bax, Bcl-2-associated X.

other cell lines may also become amenable for such a study. We could not estimate the expression level compared with normal cells as normal cells display heterogeneity including epithelia, stroma and hematopoietic cells. In addition, we did not investigate whether $\mathrm{p} 85 \mathrm{~b}$ could reverse the effect of miR-126-3p. This experiment is technically very challenging as the enforced expression of miR-126-3p and p85b is not stable due to the transient transfection technique employed. The situation would be much clearer if we could show a direct link between miR-126-3p target genes and suppression of the PI3K/PDK1/Akt pathway as alternative pathways and target proteins associated with miR-126-3p are possible. In fact, $\mathrm{Xu}$ et al reported that miR-126-3p inhibited cell proliferation and migration via the target protein ZEB1, which is associated with mesenchymal-related protein (49). We did not conduct knockdown or inhibitor experiments of endogenous miR-126-3p, downstream of the PI3K/AKT pathway or a xenograft model to demonstrate the potential application of miR-126-3p into human patients. Despite this limitation, the strength of our study is that enforced expression of miR-126-3p affected the levels of 15 proteins related to the PI3K/AKT pathway in the cell. We showed that miR-126-3p affects the PI3K/PDK1/AKT signaling pathway cascade (Fig. 7).

In cervical cancer, HPV E6 and E7 are known to play vital roles in carcinogenesis. Therefore, in this cancer, the $\mathrm{PI} 3 \mathrm{~K} / \mathrm{PDK} 1 / \mathrm{AKT}$ signaling pathway may have escaped control by endogenous miR-126-3p. Taken together with in vivo and in vitro studies, we hypothesize that miR-126-3p opposes some of the effects of E6 and E7. If so, it is not unexpected that strong expression of miR-126-3p is observed in patients with cervical cancer or precursor lesions. We now report that enforced expression of a miR-126-3p mimic negatively 
influenced cellular functions including proliferation, migration, invasion and apoptosis, and suggest that increased endogenous miR-126-3p expression may be a compensatory mechanism attempting to control carcinogenesis. Exogenous miR-126-3p and its target molecules may thus be candidates for miRNA-based cervical cancer therapy even in cases where the $P I 3 K$ gene is not mutated or amplified. For further research, an animal model is necessary in the event we are able to develop drugs using miR-126-3p.

\section{Acknowledgements}

We thank Yuko Nakagawa and Yumiko Usui for typing the manuscript. We thank Dr Takashi Iwata, Department of Obstetrics and Gynecology, School of Medicine, Keio University, Tokyo, Japan, for providing the HeLa cells.

\section{Funding}

This study was partly supported by JSPS KAKENHI (grant no. JP 26462540), and a Fujita Health University Research Grant-in-Aid.

\section{Availability of data and materials}

The analyzed datasets generated during the present study are available from the corresponding author on reasonable request.

\section{Authors' contributions}

TF and RI designed the experiments. RK and AI conducted the experiments. TF, RK, AI, HN, SO, EN and RI analyzed the data. RI, TF, RK, SO, EN and AI contributed to the writing of the manuscript. All authors read and approved the final manuscript and agree to be accountable for all aspects of the research in ensuring that the accuracy or integrity of any part of the work are appropriately investigated and resolved.

\section{Ethics approval and consent to participate}

This study was approved by the Institutional Biosafety Committee of Fujita Health University.

\section{Patient consent for publication}

Not applicable.

\section{Competing interests}

The authors declare no potential competing interests.

\section{References}

1. International agency for research on cancer, GLOBOCAN 2012: Estimated cancer incidence, mortality and prevalence. http://gco.iarc.fr/ Worldwide in 2012.

2. Gupta S, Kumar P and Das BC: HPV: Molecular pathways and targets. Curr Probl Cancer 42: 161-174, 2018.

3. Hou MM, Liu X, Wheler J, Naing A, Hong D, Coleman RL, Tsimberidou A, Janku F, Zinner R, Lu K, et al: Targeted $\mathrm{PI} 3 \mathrm{~K} / \mathrm{AKT} / \mathrm{mTOR}$ therapy for metastatic carcinomas of the cervix: A phase I clinical experience. Oncotarget 5: 11168-11179, 2014.
4. Bregar AJ and Growdon WB: Emerging strategies for targeting PI3K in gynecologic cancer. Gynecol Oncol 140: 333-344, 2016.

5. Tinker AV, Ellard S, Welch S, Moens F, Allo G, Tsao MS, Squire J, Tu D, Eisenhauer EA and MacKay H: Phase II study of temsirolimus (CCI-779) in women with recurrent, unresectable, locally advanced or metastatic carcinoma of the cervix. A trial of the NCIC Clinical Trials Group (NCIC CTG IND 199). Gynecol Oncol 130: 269-274, 2013.

6. Rashmi R, DeSelm C, Helms C, Bowcock A, Rogers BE, Rader JL, Grigsby PW and Schwarz JK: AKT inhibitors promote cell death in cervical cancer through disruption of mTOR signaling and glucose uptake. PLoS One 9: e92948, 2014.

7. Esteller M: Non-coding RNAs in human disease. Nat Rev Genetics 12: 861-874, 2011.

8. Granados López AJ and López JA: Multistep model of cervical cancer: Participation of miRNAs and coding genes. Int J Mol Sci 15: 15700-15733, 2014.

9. Ma D, Zhang YY, Guo YL, Li ZJ and Geng L: Profiling of microRNA-mRNA reveals roles of microRNAs in cervical cancer. Chin Med J (Engl) 125: 4270-4276, 2012.

10. Cheung TH, Man KN, Yu MY, Yim SF, Siu NS, Lo KW, Doran G, Wong RR, Wang VW, Smith DI, et al: Dysregulated microRNAs in the pathogenesis and progression of cervical neoplasm. Cell Cycle 11: 2876-2884, 2012.

11. Liu D, Liu C, Wang X, Ingvarsson S and Chen H: MicroRNA-451 suppresses tumor cell growth by down-regulating IL6R gene expression. Cancer Epidemiol 38: 85-92, 2014.

12. Ding H, Wu YL, Wang YX and Zhu FF: Characterization of the microRNA expression profile of cervical squamous cell carcinoma metastases. Asian Pac J Cancer Prev 15: 1675-1679, 2014.

13. Yu Q, Tong S, Yan J, Hong C, Zhai W and Li Y: Preparative separation of quaternary ammonium alkaloids from Corydalis yanhusuo $\mathrm{W}$. T. Wang by $\mathrm{pH}$-zone-refining counter-current chromatography. J Sep Sci 34: 278-285, 2011.

14. Yang Y, Song KL, Chang H and Chen L: Decreased expression of microRNA-126 is associated with poor prognosis in patients with cervical cancer. Diagn Pathol 9: 220, 2014.

15. Huang TH and Chu TY: Repression of miR-126 and upregulation of adrenomedullin in the stromal endothelium by cancer-stromal cross talks confers angiogenesis of cervical cancer. Oncogene 33: 3636-3647, 2014.

16. Liu R, Zhang YS, Zhang S, Cheng ZM, Yu JL, Zhou S and Song J: MiR-126-3p suppresses the growth, migration and invasion of NSCLC via targeting CCR1. Eur Rev Med Pharmacol Sci 23: 679-689, 2019.

17. Luo W, Yan D, Song Z, Zhu X, Liu X, Li X and Zhao S: miR-126-3p sensitizes glioblastoma cells to temozolomide by inactivating $\mathrm{Wnt} / \beta$-catenin signaling via targeting SOX 2 . Life Sci 226: 98-106, 2019.

18. Fujii T, Shimada K, Tatsumi Y, Fujimoto K and Konishi N: Syndecan-1 responsive microRNA-126 and 149 regulate cell proliferation in prostate cancer. Biochem Biophys Res Commun 456: 183-189, 2015.

19. Otsubo T, Akiyama Y, Hashimoto Y, Shimada S, Goto K and Yuasa Y: MicroRNA-126 inhibits SOX2 expression and contributes to gastric carcinogenesis. PLoS One 6: e16617, 2011.

20. Wang X, Tang S, Le SY, Lu R, Rader JS, Meyers C and Zheng ZM: Aberrant expression of oncogenic and tumor-suppressive microRNAs in cervical cancer is required for cancer cell growth. PLoS One 3: e2557, 2008.

21. Yu Q, Liu SL, Wang H, Shi G, Yang P and Chen XL: miR-126 suppresses the proliferation of cervical cancer cells and alters cell sensitivity to the chemotherapeutic drug bleomycin. Asian Pac J Cancer Prev 14: 6569-6572, 2014.

22. Kawai S, Fujii T, Kukimoto I, Yamada H, Yamamoto N, Kuroda M, Otani S, Ichikawa R, Nishio E, Torii Y, et al: Identification of miRNAs in cervical mucus as a novel diagnostic marker for cervical neoplasia. Sci Rep 8: 7070, 2018.

23. Du C, Lv Z, Cao L, Ding C, Gyabaah OA, Xie H, Zhou L, Wu J and Zheng S: MiR-126-3p suppresses tumor metastasis and angiogenesis of hepatocellular carcinoma by targeting LRP6 and PIK3R2. J Transl Med 12: 259, 2014.

24. Guo C, Sah JF, Beard L, Willson JK, Markowitz SD and Guda K: The noncoding RNA, miR-126, suppresses the growth of neoplastic cells by targeting phosphatidylinositol 3-kinase signaling and is frequently lost in colon cancers. Genes Chromosomes Cancer 47: 939-946, 2008. 
25. Xiao J, Lin HY, Zhu YY, Zhu YP and Chen LW: MiR-126 regulates proliferation and invasion in the bladder cancer BLS cell line by targeting the PIK3R2-mediated PI3K/Akt signaling pathway. Onco Targets Ther 9: 5181-5193, 2016.

26. Liu LY, Wang W, Zhao LY, Guo B, Yang J, Zhao XG, Hou N, Ni L, Wang AY, Song TS, et al: Mir-126 inhibits growth of SGC-7901 cells by synergistically targeting the oncogenes PI3KR 2 and Crk, and the tumor suppressor PLK2. Int J Oncol 45: 1257-1265, 2014

27. Qu Y, Wu J, Deng JX, Zhang YP, Liang WY, Jiang ZL, Yu QH and Li J: MicroRNA-126 affects rheumatoid arthritis synovial fibroblast proliferation and apoptosis by targeting PIK3R2 and regulating PI3K-AKT signal pathway. Oncotarget 7: 74217-74226, 2016.

28. Meng Q, Wang W, Yu X, Li W, Kong L, Qian A, Li C and Li X: Upregulation of MicroRNA-126 contributes to endothelial progenitor cell function in deep vein thrombosis via its target PIK3R2. J Cell Biochem 116: 1613-1623, 2015.

29. Vlachos IS, Paraskevopoulou MD, Karagkouni D, Georgakilas G, Vergoulis T, Kanellos I, Anastasopoulos IL, Maniou S, Karathanou K, Kalfakakou D, et al: DIANA-TarBase v7.0: Indexing more than half a million experimentally supported miRNA:mRNA interactions. Nucleic Acids Res 43 (Database Issue): D153-D159, 2015.

30. Temkin SM, Yamada SD and Fleming GF: A phase I study of weekly temsirolimus and topotecan in the treatment of advanced and/or recurrent gynecologic malignancies. Gynecol Oncol 117: 473-476, 2010.

31. Faried LS, Faried A, Kanuma T, Aoki H, Sano T, Nakazato T, Tamura T, Kuwano H and Minegishi T: Expression of an activated mammalian target of rapamycin in adenocarcinoma of the cervix: A potential biomarker and molecular target therapy. Mol Carcinog 47: 446-457, 2008

32. Tomao F, Di Tucci C, Imperiale L, Boccia SM, Marchetti C, Palaia I, Muzii L and Panici PB: Cervical cancer: Are there potential new targets? An update on preclinical and clinical results. Curr Drug Targets 15: 1107-1120, 2014

33. Wright AA, Howitt BE, Myers AP, Dahlberg SE, Palescandolo E, Van Hummelen P, MacConaill LE, Shoni M, Wagle N, Jones RT, et al: Oncogenic mutations in cervical cancer: Genomic differences between adenocarcinomas and squamous cell carcinomas of the cervix. Cancer 119: 3776-3783, 2013.

34. Wilting SM and Steenbergen RDM: Molecular events leading to HPV-induced high grade neoplasia. Papillomavirus Res 2: 85-88, 2016.

35. Macville M, Schrock E, Padilla-Nash H, Keck C, Ghadimi BM, Zimonjic D, Popescu N and Ried T: Comprehensive and definitive molecular cytogenetic characterization of HeLa cells by spectral karyotyping. Cancer Res 59: 141-150, 1999.

36. Vazquez-Mena O, Medina-Martinez I, Juárez-Torres E, Barrón V, Espinosa A, Villegas-Sepulveda N, Gómez-Laguna L, Nieto-Martinez K, Orozco L, Roman-Basaure E, et al: Amplified genes may be overexpressed, unchanged, or downregulated in cervical cancer cell lines. PLoS One 7: e32667, 2012.

37. Gonzalez E and McGraw TE: The Akt kinases: Isoform specificity in metabolism and cancer. Cell Cycle 8: 2502-2508, 2009.
38. Tavares MR, Pavan IC, Amaral CL, Meneguello L, Luchessi AD and Simabuco FM: The S6K protein family in health and disease. Life Sci 131: 1-10, 2015

39. Pearce LR, Alton GR, Richter DT, Kath JC, Lingardo L, Chapman J, Hwang C and Alessi DR: Characterization of PF-4708671, a novel and highly specific inhibitor of p70 ribosomal S6 kinase (S6K1). Biochem J 431: 245-255, 2010.

40. McCubrey JA, Fitzgerald TL, Yang LV, Lertpiriyapong K, Steelman LS, Abrams SL, Montalto G, Cervello M, Neri LM, Cocco L, et al: Roles of GSK-3 and microRNAs on epithelial mesenchymal transition and cancer stem cells. Oncotarget 8: 14221-14250, 2017.

41. Suprynowicz FA, Kamonjoh CM, Krawczyk E, Agarwal S, Wellstein A, Agboke FA, Choudhury S, Liu X and Schlegel R: Conditional cell reprogramming involves non-canonical $\beta$-catenin activation and mTOR-mediated inactivation of Akt. PLoS One 12: e0180897, 2017.

42. Engelman JA: Targeting PI3K signalling in cancer: Opportunities, challenges and limitations. Nat Rev Cancer 9: 550-562, 2009.

43. Kim MS, Kim JH, Bak Y, Park YS, Lee DH, Kang JW, Shim JH, Jeong HS, Hong JT and Yoon DY: 2,4-bis (p-hydroxyphenyl)2-butenal (HPB242) induces apoptosis via modulating E7 expression and inhibition of PI3K/Akt pathway in SiHa human cervical cancer cells. Nutr Cancer 64: 1236-1244, 2012.

44. Bahrami A, Hasanzadeh M, Hassanian SM, ShahidSales S, Ghayour-Mobarhan M, Ferns GA and Avan A: The potential value of the PI3K/Akt/mTOR signaling pathway for assessing prognosis in cervical cancer and as a target for therapy. J Cell Biochem 118: 4163-4169, 2017.

45. Lee CM, Fuhrman CB, Planelles V, Peltier MR, Gaffney DK, Soisson AP, Dodson MK, Tolley HD, Green CL and Zempolich KA: Phosphatidylinositol 3-kinase inhibition by LY294002 radiosensitizes human cervical cancer cell lines. Clin Cancer Res 12: 250-256, 2006.

46. Xie G, Wang Z, Chen Y, Zhang S, Feng L, Meng F and Yu Z: Dual blocking of PI3K and mTOR signaling by NVP-BEZ235 inhibits proliferation in cervical carcinoma cells and enhances therapeutic response. Cancer Lett 388: 12-20, 2017.

47. Cho SY, Choi M, Ban HJ, Lee CH, Park S, Kim H, Kim YS, Lee YS and Lee JY: Cervical small cell neuroendocrine tumor mutation profiles via whole exome sequencing. Oncotarget 8: 8095-8104, 2017.

48. Gagliardi PA, di Blasio L and Primo L: PDK1: A signaling hub for cell migration and tumor invasion. Biochim Biophys Acta 1856: 178-188, 2015

49. Xu J, Wang H, Wang H, Chen Q, Zhang L, Song C, Zhou Q and Hong Y: The inhibition of miR-126 in cell migration and invasion of cervical cancer through regulating ZEB1. Hereditas 156: 11, 2019.

(i) $\Theta$ This work is licensed under a Creative Commons Attribution-NonCommercial-NoDerivatives 4.0 International (CC BY-NC-ND 4.0) License. 